\title{
Mashare - Earth Observation
}

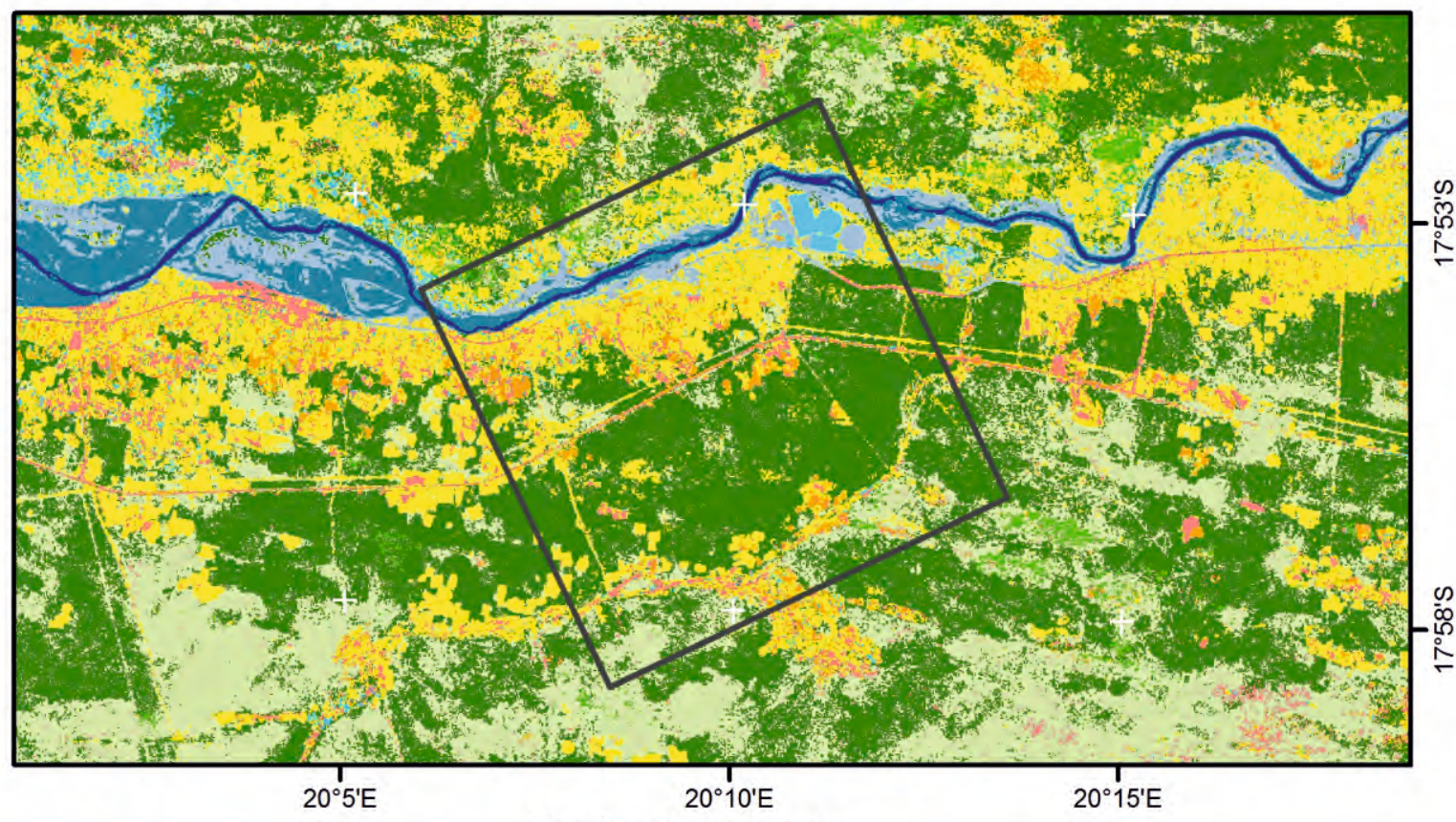

Land use/cover

Land use/cover types

classification for 2009

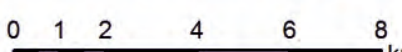

Data source

Landsat 5 TM provided by USGS

Projection/Datum

UTM, WGS 1984, Zone 34 S

\begin{tabular}{|c|c|}
\hline Mixed Burkea woodlands & Irrigated fields \\
\hline Thornbush savannah & Settlements, impervious surfaces \\
\hline Bare ground & Open water \\
\hline Burned, recently & $\begin{array}{l}\text { Seasonally flooded grasslands } \\
\text { and reed beds }\end{array}$ \\
\hline Active fields & Seasonally flooded grasslands \\
\hline Fallows & (sparse) \\
\hline
\end{tabular}

Fig. 1: Land use/cover classification based on Landsat 5 TM data for 2009.
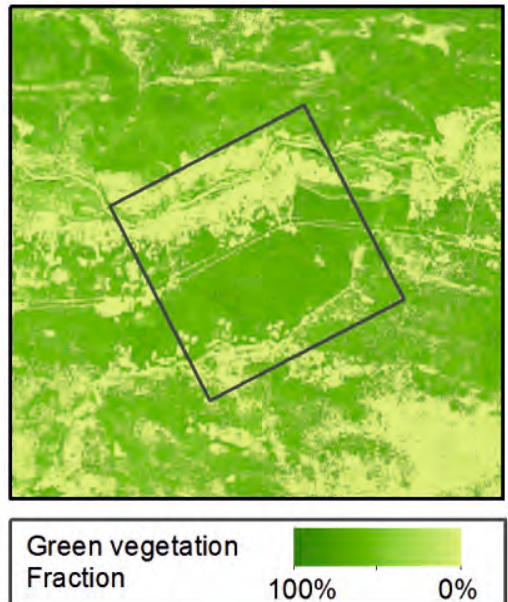

Spectral Mixture
Analysis Mashare
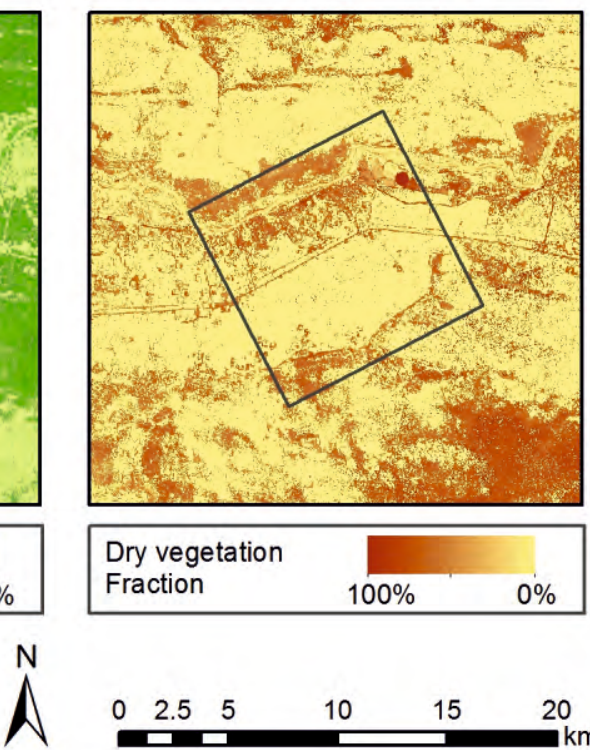
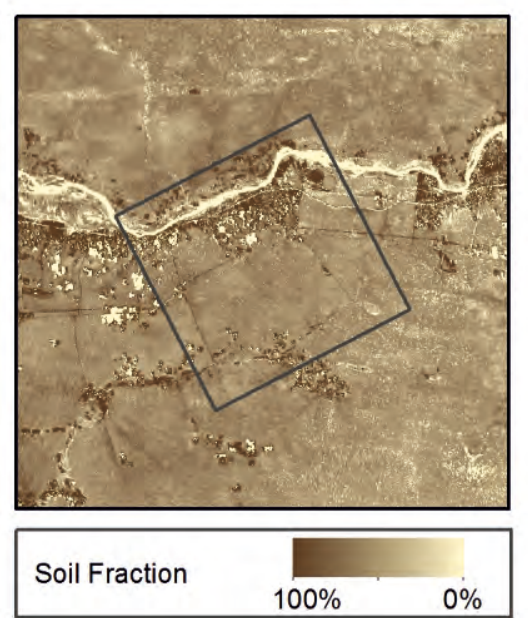

Data source

Landsat 5 TM 27/05/2009

Projection/Datum

UTM, WGS 1984, Zone 34S

Fig. 2: Spectral unmixing result of Landsat 5 TM data (2008). Displayed are the fractions of the three endmembers "green vegetation" (left), "dry vegetation" (centre) and "soil" (right). 
The Mashare land cover map of the year 2009 was derived from a bi-seasonal Landsat 5 TM data-set (path 177, row 72) with images from March and May 2009 (Fig. 1). The Okavango River and its floodplain form the border between Angola in the north and Namibia in the south. Land cover in the Mashare area is dominated by arable land for subsistence farming and mixed Burkea woodlands on Kalahari sands. Arable land is mainly concentrated along the river on the old floodplain but also stretches into the hinterland. Irrigated fields are located in the north-eastern part of the core site and belong to the Mashare Irrigation Training Centre (MIT). The land cover map also illustrates those parts of the woodlands that have been burned within the observation period.

At the time of the year when the images were taken, large parts of the woodlands still exhibit green vegetation cover whereas fields are characterized by high fraction of dry vegetation (Fig. 2). This is clearly related to the growing cycle of the crops which are grown exclusively during the rainy season. Hence at this point in the year, fields are being harvested.
The EVI time profiles of rainfed and irrigated agriculture clearly show a huge difference in the productivity of the two land use classes (Fig. 3). Whereas rainfed agriculture is characterized by a less distinct annual cycle with maximum values of 0.35 , the time profile of the irrigated fields, which was established in the early 2000 s, shows a very pronounced annual cycle with maximum values reaching 0.8 . Moreover, the EVI profile shows that the irrigated field has undergone a management change in 2007/2008, when a double cropping cycle was implemented.

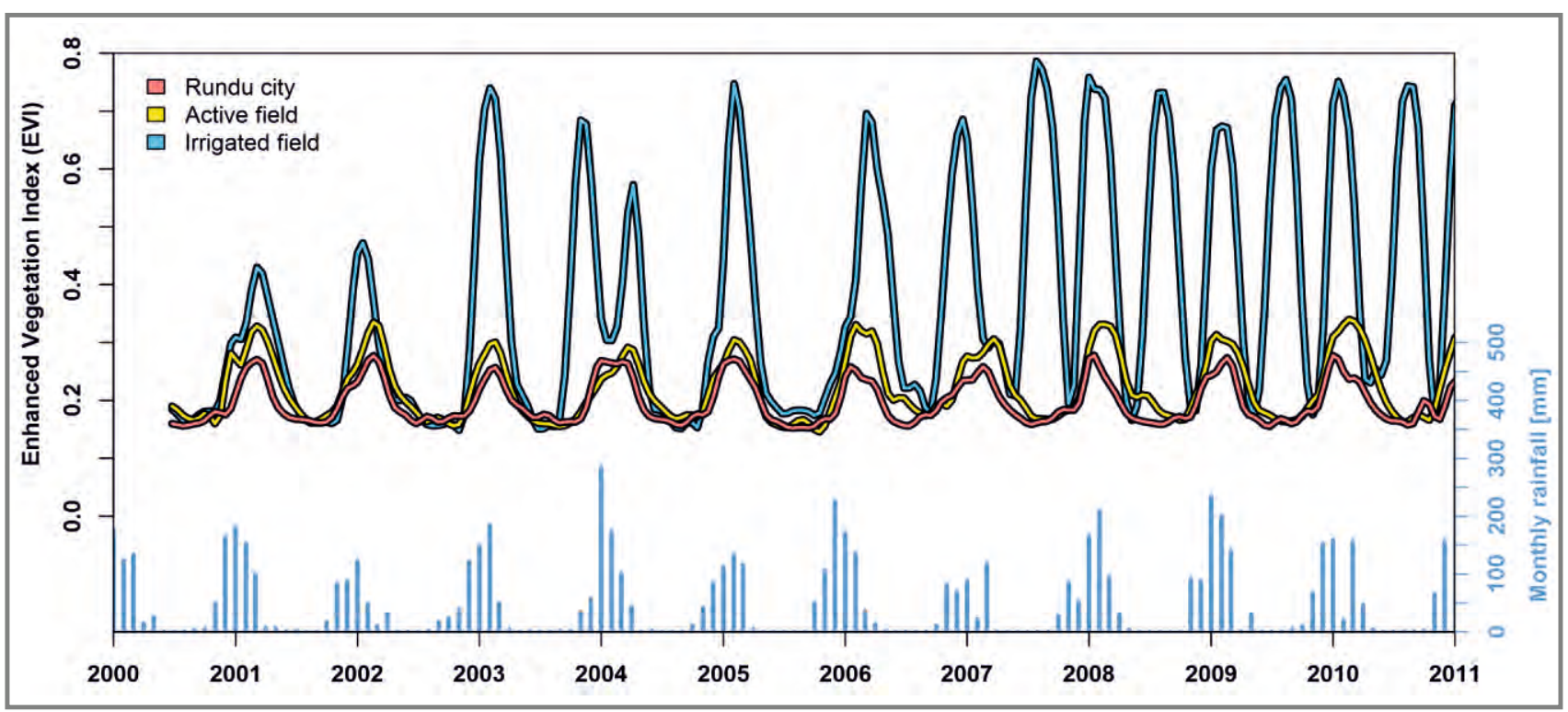

Fig. 3: MODIS EVI profiles for the city of Rundu, for an arable land and an irrigated land from 2000 to 2010. Also given is the monthly rainfall for this time period.

\section{Phenology parameters derived from MODIS EVI time series (2000-2012)}
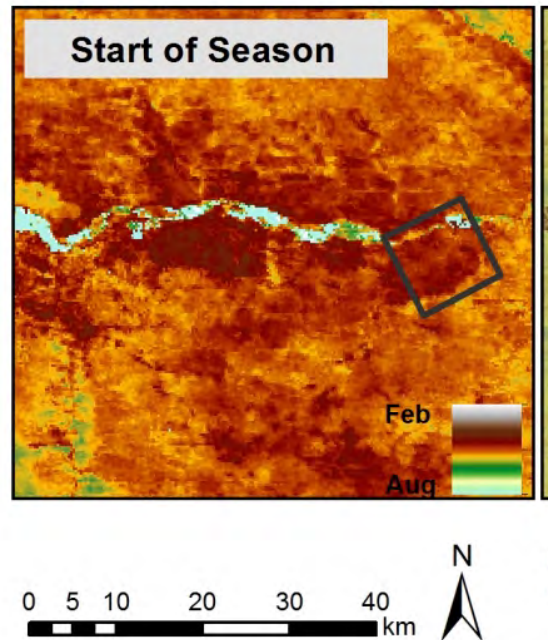

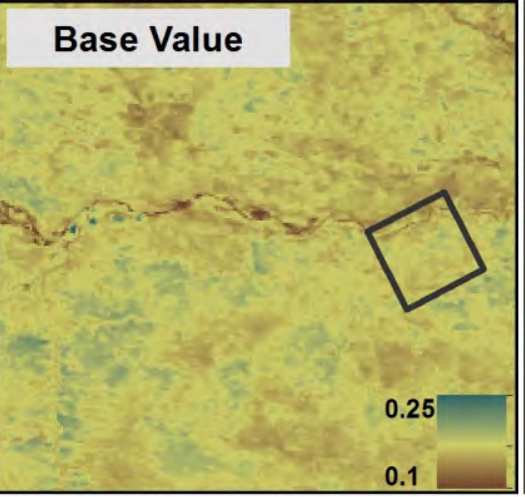

\section{Small Integral}

Projection/Datum:

UTM, WGS 1984, Zone 34S
Data source:

The phenology parameters were derived with the software package TIMESAT (Jönsson and Eklundh 2002) based on the MODIS 16-day EVI product (MOD13Q1) provided by EOSDIS (NASA).

Fig. 4: Phenology parameters derived from MODIS EVI time series with the software package TIMESAT. Displayed are the "start of the season" (left), the "base EVI value" (centre) and the "small integral" (right). 


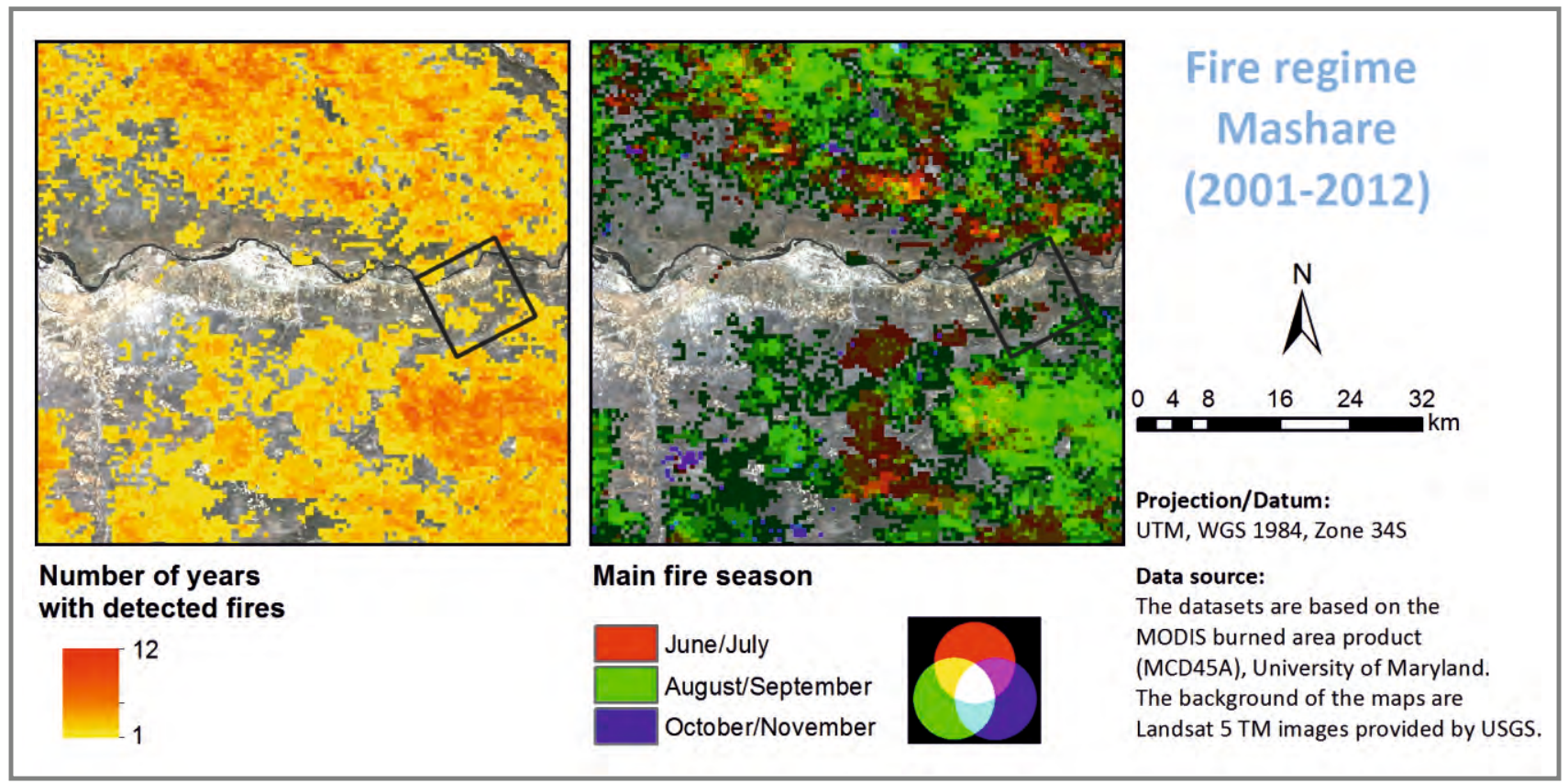

Fig. 5: Number of years with detected fires (left) and main fire season (right) derived from the MODIS burned area product within the observation period 2001 to 2012.

The "start of season" in November/December is quite homogenous throughout the area except for the floodplains. This could be an artefact caused by the annual inundation (Fig. 4). The amplitudes of the EVI for the different land cover classes are rather small compared to the Cusseque core site; only the irrigated fields show very high amplitude of values. The "small integral" indicates that the productivity of traditionally managed fields is very low, whereas the annual productivity of the mixed Burkea woodlands only reaches a medium level.

The fire maps show that the woodland areas burn regularly and the main fire season is in August and September (Fig. 5). However, fires might also occur earlier or later in the year. It is very striking that areas with high population densities and consequently intense use by humans are not affected by fires. This is true for the city of Rundu situated in the western part of the area as well as for the villages of the core site along the Okavango River.

\section{Acknowledgements}

This study was funded by the BMBF (The Future Okavango project). For details see authors' general acknowledgements in this volume.

Responsible authors: A. Röder, A. Schneibel, M. Stellmes, D. Frantz 
